\title{
Removal of nitrates from groundwater in remote indigenous settings in arid Central Australia
}

\author{
Helen Salvestrin ${ }^{\mathrm{a}}$, Prasanthi Hagare ${ }^{\mathrm{b}, *}$ \\ ${ }^{a}$ Center for Appropriate Technology, PO Box 8044, Alice Springs, NT 0870, Australia \\ Tel.+61 88951 4340; Fax.+6188951 4333; email: helen.salvestrin@icat.org.au \\ ${ }^{b}$ School of Civil and Environmental Engineering, University of Technology, Sydney (UTS), PO Box 123, Broadway, NSW 2007, Australia \\ Tel.+61 29514 1952; Fax. +61 29514 2633; email:Prasanthi.Hagare@uts.edu.au
}

Received 31 March 2009; Accepted 31 August 2009

\begin{abstract}
A B S T R ACT
Naturally occurring elevated levels of nitrates are detected in many of the groundwater bores in the arid zone of Central Australia. Such levels are associated with anemia in young babies, pregnant women and other vulnerable groups. Further, there is evidence that links long-term exposure to elevated levels of nitrates with gastric cancer. In many parts of arid Central Australia alternative sources of water are not available. The capacity to operate and maintain water treatment and supply systems in remote Indigenous communities varies due to access and levels of service provision, mobility of the residents and balance of skills within the communities. A need has thus been identified for a low maintenance nitrate removal system. Conventional treatment processes do not remove nitrates. Alternatives, such as reverse osmosis, ion exchange or biological denitrification are either complex, energy and water intensive, expensive, produce waste products requiring disposal or require continual maintenance and monitoring. Such preconditions are not able to be met in remote Indigenous communities. This paper reviews the problems of nitrates in the arid zone of Central Australia and explores existing technologies for their removal, relative to remote Indigenous settings. It identifies a need for further investigations to tailor technology to the unique social, economic and cultural characteristics of these settings.
\end{abstract}

Keywords: Nitrate; Groundwater; Physical processes; Physico-chemical processes; Central Australia; Denitrification

\section{Introduction}

Naturally elevated levels of nitrate occur in otherwise potable groundwaters across the arid zone of Central Australia, often exceeding the Australian Drinking Water Guidelines. The National Health and Medical Research Council [1] recommends that water used for consumption by infants less than 3 months of age contain no more than $50 \mathrm{mg} / \mathrm{L}$ nitrate. For adults and children

${ }^{*}$ Corresponding author. over 3 months, up to $100 \mathrm{mg} / \mathrm{L}$ nitrate can safely be consumed.

Health concerns around the consumption of nitrates are primarily around its reduction to nitrite [1-3]. Nitrite supports the oxidation of normal haemoglobin $(\mathrm{Hb})$ to methaemoglobin (metHb), which is unable to transport oxygen to the tissue. The resulting condition is known as methaemoglobinaemia, and is more likely to affect young infants due to the greater susceptibility of fetal $\mathrm{Hb}$ to oxidation to metHb and a deficiency of the metHb reductase [3]. Pregnant women also have

Presented at CESE-2009, Challenges in Environmental Science E Engineering, 14-17 July, 2009, Townsville, Queensland, Australia. doi: 10.5004/dwt.2009.8śŚ 
greater susceptibility to the toxic effects of nitrates due to lower levels of metHb reductase [1]. Other factors affecting susceptibility to methaemoglobinaemia may include lower levels of gastric acid and thus higher levels of gastric bacteria which enhance the reduction of nitrates to nitrites.

There is also some concern around nitrates and gastric cancer, congenital malformations and cardiovascular problems in humans, but there has been no definitive confirmation related to any of these issues [3].

\subsection{Nitrates in groundwater}

Naturally occurring nitrate is a contaminant affecting otherwise-potable groundwaters across the arid zones of Central Australia [4]. Whilst anthropogenic sources of nitrate are largely from intensive agricultural activities, animal wastes and sewage effluent disposal, an imbalance between the non-anthropogenic processes of nitrate accumulation and denitrification can contribute to elevated levels of nitrates $[2,5]$. Nitrates are fixed in soils by bacteria, and have been identified in relatively high concentrations below open ground, spinifex and stands of young mulga trees [6]. Particularly high concentrations, however, have been recorded below the mounds of particular species of termites [5]. Natural denitrification processes are affected by the amount of organic carbon, soil moisture and temperatures. An imbalance of these variables in arid zones in Australia leads to inefficient denitrification and subsequently contributes to elevated levels of nitrate-N. Heavy rains can then wash the accumulated nitrates into the water table [3]. Cyanobacteria also contribute to fixed nitrogen in arid regions of Australia [7].
Studies have identified non-anthropogenic nitrate concentrations from 3 to $280 \mathrm{mg} / \mathrm{L}$ in the Ti Tree Basin in Central Australia [8], up to $50 \mathrm{mg} / \mathrm{L}$ around Yulara, Northern Territory [4], up to $131 \mathrm{mg} / \mathrm{L}$ in the Pitjantjatjara Lands in South Australia [9] and up to $132 \mathrm{mg} / \mathrm{L}$ at Lake Way in Western Australia [10].

Table 1 summarizes chemical analyses of groundwater collected from five sites across the arid zone of the Northern Territory, indicating high salinity and high total dissolved solids. Figure 1 shows the location of these bores. The table also indicates that the concentration of sulfate, chloride and nitrate and other parameters varies for each location and does not show a consistent trend. This signifies a research issue while dealing with treatment and water supply.

This paper first explores the context of remote Indigenous settlements, with respect to the natural environment, Indigenous culture and water supply infrastructure and service provision, to highlight opportunities and barriers for water supply management. Existing treatment methodologies for nitrate removal are then explored in relation to specific criteria developed relevant to this context.

\section{Remote Indigenous community context}

Environmentally, arid Australia presents a unique setting. Mean maximum temperatures of 25 to 40 degrees Celsius can persist for up to eight months of the year [16]. During winter, temperatures drop below freezing. Vegetation is often sparse, leaving exposed soil which, during periods of high winds, may contribute to dust storms.

Table 1

Chemical analyses (mg/L) of groundwaters-various sites in arid Australia.

\begin{tabular}{lccccc}
\hline Site & Yulara $^{\mathrm{a}}$ & Mulga bore $^{\mathrm{b}}$ & Urlampe $^{\mathrm{c}}$ & Ali curung $^{\mathrm{d}}$ & Mount denison $^{\mathrm{e}}$ \\
\hline Year of sample & 2000 & 2008 & 2007 & 2008 & 2005 \\
Total dissolved solids (mg/L) & 2020 & 2000 & 3350 & 1011 & 1250 \\
pH & 7.3 & 8.1 & 7.5 & 8.1 & 8 \\
Sodium (mg/L) & 337 & 300 & 455 & 238 & 280 \\
Potassium (mg/L) & 47 & 155 & 250 & 53 & 17 \\
Calcium (mg/L) & 160 & 93 & 175 & 34 & 44 \\
Magnesium (mg/L) & 73 & 192 & 202 & 0.0005 & 446 \\
Alkalinity (mg/L) & 186 & 240 & 1150 & 114 & 120 \\
Sulfate (mg/L) & 570 & 591 & 71 & 227 & 225 \\
Chloride (mg/L) & 543 & 240 & & 75 & 143 \\
Nitrate (mg/L) & 69 & & &
\end{tabular}




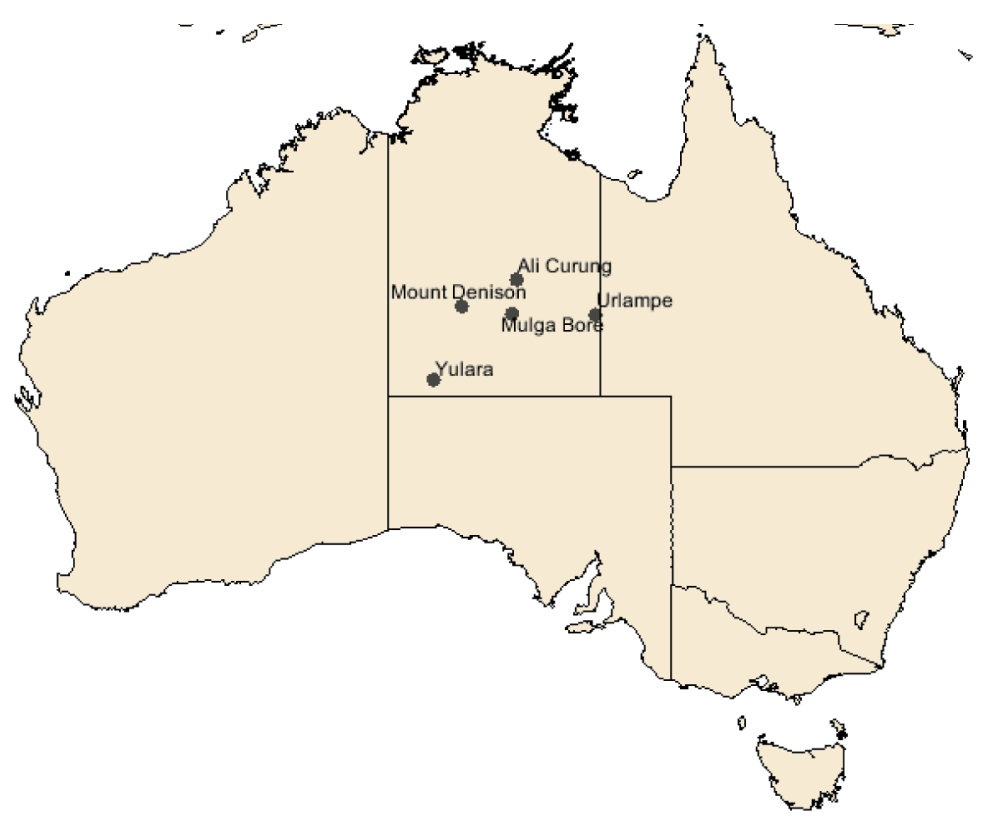

Fig. 1. Location of a selection of bores with elevated nitrates in Northern Territory.

Water resources in these arid environments are often scarce, with a short wet season over summer, with less than $300 \mathrm{~mm}$ of rainfall each year [17]. Few permanent surface water bodies exist, and groundwater resources are often low yielding, as little as 0.05 to $5.0 \mathrm{~L} / \mathrm{s}$ in granite and shale aquifers throughout Northern Territory [18].

A typical water supply system in a remote Indigenous community constitutes of one or more groundwater bores pumped, using either a diesel or solar powered pump, to a header tank and distributed under gravity to individual households and other community buildings. Treatment is generally limited to disinfection at larger communities only.

Water management in remote Indigenous communities has particular challenges associated with access and service provision, mobility of Indigenous people and limited resources within communities.

Indigenous communities largely exist on the margins of the regional economy [19]. The large distances from often even the smallest rural service centres, poorly connected transport services and often poor communications affects the level of services attained within communities [20]. Access to service centres may also be affected during the wet season when unsealed roads may be cut off for several months. Service providers are often based hundreds of kilometers from communities, with specialist technicians even further away. The 1999 Indigenous Community Housing and Infrastructure Needs Survey identified 96 service centres across remote Australia, servicing a collective population of approximately 80,000 people.
Further, the commitment by local, state and federal governments to the provision, operation and maintenance of adequate water supply with respect to both quality and quantity in remote communities varies across Australia, from the initial support only to establish a basic water supply in small outstations, to scheduled, regular maintenance programs of key equipment and provision of fuel to a dedicated Essential Services Officer whose responsibilities may include the daily operation and monitoring of the system, supported by State institutions for larger maintenance issues.

Limited levels of services that are provided may mean the inability to provide daily operational support, infrequent servicing and maintenance and long lagtimes for emergency call-outs, all of which have major implications on the complexity of infrastructure that can be successfully installed and operated on remote communities.

Indigenous people often exhibit relatively high rates of mobility both within and between communities and travel to other places, including regional centres [19]. Mobility patterns are more commonly over shorter periods of time (days or weeks), rather than months $[19,21]$ and are strongly associated with Indigenous social and economic needs and regional influences, amongst other factors. For instance, ceremonial business may result in an influx of people from other communities to one central location increasing a typical population of 60 people to 200 people. Of particular interest to community-based operation and maintenance of their own infrastructure lies in the availability of human assets - the education, 
training and skills to operation and maintain the system. Given the gender and age patterns in mobility, it can be difficult to support a regular community-based team for water system management.

The ability to operate and maintain infrastructure can be further limited by the lack of physical resources such as tools and plant equipment and the lack of financial resources for ongoing consumables, such as water treatment chemicals or fuel.

Based on these factors, often the least-risk approach to managing water systems in remote Indigenous communities is to reduce the need for daily or regular operation and support.

\section{Current treatment options and their feasibility}

Given the environmental, social, political and financial context of remote Indigenous communities, an appropriate treatment methodology must meet the following criteria:

- Low energy requirements, owing to a high dependence on either diesel generators or power stations or renewable energy such as solar;

- Waste less water as a byproduct of the treatment process, due to the scarcity and vulnerability of water supplies; effective management of waste products can also be a critical issue in remote communities;

- Be robust enough to withstand environmental conditions of the arid zone; that is, high temperatures, low humidity and plenty of dust;

- Require little attention for both operation and maintenance, both in frequency and need for complex servicing by highly specialized technicians;

\section{Additional desirable criteria include:}

- The ability to be turned off for short periods (from days up to several months) if a community is uninhabited;

- Be a low cost treatment methodology, particularly with respect to ongoing maintenance costs.

Conventional treatments are not effective nitrate removal methodologies. Where sufficient alternative potable water sources, such as rainwater or surface water, are not available for blending, which is often the case in the arid zone, the only effective removal systems are reverse osmosis, ion exchange and biological denitrification

\subsection{Reverse osmosis}

Reverse osmosis is a physico-chemical process where pressure forces water across a semipermeable membrane, leaving the nitrate ions behind $[22,23]$. The process is driven using pressures exceeding its osmotic pressure, which means the higher the concentration of the salts in the input water, the higher the pressure required to drive the process. Pre-treatment may be required to protect the membranes, particularly in the case of very hard water in the input stream, adding cost and maintenance requirements to the system and additional possible by-products.

Reverse osmosis fails to meet most of the criteria developed for nitrate removal in remote Indigenous communities. Whilst manufacturers are now supplying some units complete with stand alone solar systems, reverse osmosis units for small communities may require up to $1,400 \mathrm{kPA}$ of pressure for water with up to $1,000 \mathrm{mg} / \mathrm{L}$ of total dissolved solids [23]. Household units may operate with as little as $280 \mathrm{kPA}$, which is still far higher than that available in a typical gravity-fed water supply system in Central Australia. These units would also require far more maintenance than the community unit.

The by-product from the system can be up to $25 \%$ of the input stream on community systems or even greater for household units (up to 90\%) [23]. Disposal of this reject water can be costly in terms of money and human resources.

Maintenance of reverse osmosis units is high requiring regular checks of pressure, back flushing, replacing of filters and checking of membranes. These tasks require skilled technicians, generally not available in the vicinity of remote Australian communities. Mobilisation costs alone are high.

Reverse osmosis units may be closed down for periods of non-use, through the use of chemicals to protect the membrane. However, this process would require the attention of a skilled technician.

Empirical data is emerging regarding the ability of reverse osmosis units to withstand harsh arid zone conditions-a small self-contained solar unit has recently been installed at the Desert Knowledge Australia Solar Centre in Alice Springs, Northern Territory and is being monitored [24]. Further, similar units have been installed and used effectively in similar environments in Pakistan and Mauritania [25].

\subsection{Ion exchange}

Ion exchange is a physico-chemical process which exchanges ions in solution, with chemically equivalent numbers of ions associated with the resin [22]. Typically, nitrate ions are removed by their replacement with a chloride-based resin.

The advantages of the ion exchange process are that process control is easier and it is not affected by ambient temperature. Daily energy requirements are significantly less than for reverse osmosis. 
The key disadvantage of ion exchange is associated with the need for regeneration of the exchange resin when all of the sites on the resin are occupied with the targeted contaminant. This process produces a small stream of concentrated nitrate ions, the disposal of which is more difficult and costly than for the byproducts of reverse osmosis [23]. The most appropriate option for arid Australia would be through evaporation ponds, which have major implications for maintenance and safety of the residents.

\subsection{Biological denitrification}

Biological denitrification is a microbial respiratory process where particular microorganisms use nitrate, instead of oxygen, for an electron acceptor for respiration. When this occurs under the right environmental conditions, including the right nutrients, $\mathrm{pH}$ and electron donor availability, nitrate is reduced to nitrogen gas. The denitrifying organisms require carbon and energy substrates for the reduction reaction. The process can take place within the aquifer (in situ treatment) or in above-ground bioreactors (ex situ) [22]. Previous experiments have used a variety of carbon sources from sawdust, mulch, newspaper and cotton to methanol, cellulosic material, acetic acid, ethanol, glucose or molasses [26,27].

Ex situ reactors would consist of one or more large tanks, partially filled with a variety of support materials for the denitrifying biomass. Smith et al., [5] investigated the possibility of using biological denitrification using immobilized denitrifying bacteria with methanol as a carbon source. This system was studied with the main purpose of using small scale treatment systems for small settlements in remote areas. The study showed that is possible to achieve a total removal of nitrate, nitrite and methanol within a range of 1.10-1.75. Bidhendi et al., [28] investigated a pilot fixed bed system to study the removal of nitrates from groundwater. Their studies showed that using acetic acid as a carbon donor (instead of methanol so as to reduce toxicity), a 77\% removal of nitrates is possible. While the nitrate levels would be reduced through any of these processes, levels of suspended solids, organic matter, turbidity and bacteria may still be such that secondary treatment may be required. Dissolved oxygen would also be low. Careful monitoring of input levels of nitrate and the resultant amount of carbon substrate required is necessary to obtain appropriate levels of nitrate and carbon substrate in the finished water [23]. Installation costs and complexity of such units are high.

In situ biological denitrification offer advantages over ex situ owing to the need for less equipment, low energy consumption and low interference with surface activity. Further, some secondary treatment such as filtration and oxygenation, may take place within the aquifer provided that distances and retention times are adequate [23]. Most in situ denitrification processes involve injecting the carbon source into the aquifer. A simple in situ approach involves injecting the carbon substrate into a single recharge well and extracting the denitrified water from a single pumping well. An alternative is the use of small diameter injection wells arranged around a large diameter uptake well.

However, in situ processes present difficulties associated with process management and control and monitoring of the process, requiring constant attention by skilled technicians to ensure the effectiveness of the process.

\section{Discussion}

Maintenance of drinking water supply systems in remote Indigenous communities in Australia is often affected by a lack of resources, skills and limited access. Water supply systems are even more vulnerable when they are dependent on only one source of water, as is often the case in the arid zone of Central Australia, where groundwater is the only source.

As discussed above, technology is available that can efficiently remove nitrates from water.

Their effectiveness in the context of remote Indigenous communities, however, is not known, particularly with regard to their operation and maintenance. The increasing use of solar energy in Central Australia presents an opportunity for powering various treatment methodologies.

The need for regular monitoring means that nitrate removal through biological denitrification is not appropriate. Additional criteria for successful nitrate removal methodologies include low energy requirements, little wastage of water and robustness.

'Point of use' modular systems, be they reverse osmosis or ion exchange, to treat water at the household level for domestic consumption (that is cooking and drinking) only may provide some advantage in their relative simplicity compared to community-wide applications. Overall cost and relative volumes of wastewater may be reduced. However, further investigations are warranted to determine the design capacity of such a system, an effective way to determine when the modules need replacement and how the by-product can be collected, stored and disposed.

\section{Conclusion}

It is apparent from the review presented in this paper that future investigations are required, to study the variations in nitrate concentrations in groundwaters in specific sites with respect to different variables, and to study 
the feasibility of using treatment technologies to remove nitrates given the social, economic and cultural context of Indigenous communities. The ability of the support agencies to provide operational and maintenance support must be met by proposed treatment technologies significantly to ensure that the treatment is effective and continuous.

\section{References}

[1] National Health and Medical Research Council. Australian Drinking Water Guidelines. National Water Quality Management Strategy. 2004 cited; Available from: http://www.nhmrc .gov .au/publications/synopses/_files/adwg_11_06.pdf.

[2] O. Schmoll, G. Howard, J. Chilton and I. Chorus, Protecting Groundwater for Health. Managing the Quality of Drinkingwater Sources. 2006, London: World Health Organisation.

[3] World Health Organization. Nitrate and nitrite in drinkingwater. Background document for development of WHO Guidelines for Drinking-water Quality. 2007 [cited 2009]; Available from: http://www.who.int/water_sanitation_health/dwq/ chemicals/nitratenitrite2ndadd.pdf.

[4] C.J. Barnes, G. Jacobson and G.D. Smith, The origin of highnitrate ground waters in the Australian arid zone, J. Hydrol., 137 (1992) 181-197.

[5] G.D. Smith, C.J. Barnes, R.M. Lynch, C.J. Byrne and G. Jacobson, Possible denitrification technology for small settlement water supplies, Water Res. Manag., 7 (1993) 69-90.

[6] R. Beckmann, Unwanted nitrates: the termite connection, ECOS. Towards a Sustainable Future, 68 (1991) 34-35.

[7] G.D. Smith, R.M. Lynch, G. Jacobson and C.J. Barnes, Cyanobacterial nitrogen fixation in arid soils of Central Australia, FEMS Microbiology Ecology, 74 (1990) 79-90.

[8] G.A. Harrington, A.L. Herczeg and P.G. Cook, Groundwater Sustainability and Water Quality in the Ti-Tree Basin, Central Australia, in Technical Report 53/99. 1999, CSIRO Land and Water: Glen Osmond.

[9] J. Fitzgerald, D. Cunliffe, S. Rainow, S. Dodds, S. Hostetler and G. Jacobson, Groundwater quality and environmental health implications, Anangu Pitjantjatjara Lands, South Australia 1999, Bureau of Rural Sciences: Canberra.

[10] A.W. Mann and R.L. Deutscher, Hydrogeochemistry of a calcrete containing aquifer near Lake Way, Western Australia, J. Hydrol., 38 (1978) 357-377.

[11] Natural Resources Environment the Arts and Sport. Bore Report RN013365. 24 June 2009 cited; Available from: http:// www.ntlis.nt.gov.au/imfPublic/imf.jsp?site=nreta.

[12] Northern Territory Government. Diagnostic Services Water Chemistry Laboratory, Project: Mulga Bore - General Chemical. Job No: W08_0482. 2008, Northern Territory Government. Diagnostic Services Water Chemistry Laboratory.

[13] Centre for Appropriate Technology, Report on Water Activities in the Plenty Highway Region May 2007-May 2008. 2008, Centre for Appropriate Technology.
[14] Power and Water Corporation. Annual Drinking Water Quality Report 2008 - Indigenous Communities of the Northern Territory. 2008 [cited 200923 June]; Available from: http:// www.powerwater.com.au/_data/assets/pdf_file/0019/9307/ Water_Quality_Report_2008.pdf.

[15] Northern Territory Government. Diagnostic Services Water Chemistry Laboratory, Project: Mt Denison Excision. Job No: W05_0072. 2005, Northern Territory Government. Diagnostic Services Water Chemistry Laboratory.

[16] Bureau of Meteorology. Monthly Climate Statistics for 'YULARA AERO' [015635]. Climate statistics for Australian locations 2008 [cited 200823 April]; Available from: http:// www.bom.gov.au/climate/averages/tables/cw_015635.shtml.

[17] Bureau of Meteorology. Monthly Climate Statistics for 'WILUNA' [013012]. Climate Statistics for Australian Locations 2009 [cited 200911 March]; Available from: http://www.bom. gov.au/clim_data/cdio/tables/text/IDCJCM0039_013012.csv.

[18] S.J. Tickell, Groundwater of the Northern Territory 1: 2,000,000 scale. 2008, Department of Natural Resources Environment and the Arts, Northern Territory.

[19] J. Taylor, D. Brown and M. Bell, Population Dynamics and Demographic Accounting in Arid and Savanna Australia: Methods, Issues and Outcomes, in Desert Knowledge Cooperative Research Centre Report 16. 2007, Desert Knowledge Cooperative Research Centre Report: Alice Springs.

[20] J. Taylor, The spatial context of indigenous service delivery. CAEPR Working Paper No. 16/2002 2002 [cited 200913 March]; Available from: http://www.anu.edu.au/caepr/Publications/ WP/CAEPRWP16.pdf.

[21] P. Memmott, S. Long and L. Thomson, Mobility of Aboriginal people in rural and remote Australia, AHURI Research \& Policy Bulletin, 69 (2006).

[22] L.W. Canter, Nitrates in Groundwater, CRC Press, Inc., New York, 1997.

[23] W.J. Hunter, Remediation of drinking water for rural populations, in Nitrogen in the environment: sources, problems, and management, J.L. Hatfield and R.F. Follett (Eds.), Academic Press, 2008.

[24] Desert Knowledge Australia. Solar Centre. Solar Water System. 2009 [cited $200930 \mathrm{March}$ ]; Available from: http://www .dkasolarcentre.com.au/go/technologies/solar-water-system.

[25] P. Wochele, Application of reverse osmosis units, H. Salvestrin, Editor, Alice Springs, 2008.

[26] C. Della Rocca, V. Belgiorno and S. Meriç, Cotton-supported heterotrophic denitrification of nitrate-rich drinking water with a sand filtration post-treatment, Water SA, 31 (2005) 229-236.

[27] C. Della Rocca, V. Belgiorno and S. Meriç, Overview of in-situ applicable nitrate removal processes, Desalination, 2004 (2007) $46-62$.

[28] G.R.N. Bidhendi, T. Nasrabadi, H.R.S. Vaghefi and H. Hoveidi, Biological nitrate removal from water resources, International Journal of Environmental Science and Technology, 3 (2006) 281-287. 